\title{
Larval dispersal reveals regional sources and sinks in the Great Barrier Reef
}

\author{
Michael Bode ${ }^{1,3, *}$, Lance Bode ${ }^{1}$, Paul R. Armsworth ${ }^{2,4}$ \\ ${ }^{1}$ School of Mathematical and Physical Sciences, James Cook University, Townsville 4811, Queensland, Australia \\ ${ }^{2}$ Department of Biological Sciences, Stanford University, Stanford, California 94305, USA \\ ${ }^{3}$ Present address: Department of Mathematics, University of Queensland, Brisbane 4072, Queensland, Australia \\ ${ }^{4}$ Present address: Department of Animal and Plant Sciences, University of Sheffield, Sheffield S10 2TN, UK
}

\begin{abstract}
We analysed simulated connectivity patterns for reef fish larvae in the Cairns section of the Great Barrier Reef, and identified 2 key subregions that exhibit regional scale source-sink dynamics. The source and sink were separated latitudinally by a boundary at $16.1^{\circ} \mathrm{S}$, with the source subregion lying to the north. Larval transport between the 2 subregions was predominantly unidirectional, from north to south. Only a few local populations, described here as 'gateway reefs', were able to transport larvae from the sink subregion to the source subregion and thus maintain the connectedness of the metapopulation. The northern subregion was able to persist without external larval supply, but when conditions were recruitment limited, the southern subregion depended on larval supply from the north to persist. The relative autonomy of the northern subregion, and its importance in sustaining the southern subregion, will influence the effectiveness of conservation efforts.
\end{abstract}

KEY WORDS: Larval dispersal $\cdot$ Source-sink $\cdot$ Coral reef fish $\cdot$ Metapopulation dynamics Resale or republication not permitted without written consent of the publisher

\section{INTRODUCTION}

Coral reef fish on the Great Barrier Reef (GBR) are structured into 'marine metapopulations' (Roughgarden et al. 1985), where reefs support 'local populations' of fish. However, unlike terrestrial metapopulations that are characterised by low levels of migration (Hanski 1999), patches in marine metapopulations are strongly interconnected by pelagic larval dispersal (Botsford et al. 2003).

Larval recruitment varies regionally, and this largescale variation affects population dynamics on smaller scales. On the GBR, regional variation in recruitment densities determines the relative importance of preand post-settlement processes for predicting adult abundances of coral reef fish (Doherty 1991, Jones 1991, Doherty \& Fowler 1994, Caley 1995, Caley et al. 1996, Doherty 2002). Doherty (2002) speculated that some of this large-scale variation in recruitment might be caused by the existence of demographic source and sink subregions in the fish metapopulation.
To understand such interactions between local and regional dynamics, we must analyse these metapopulations over multiple spatial scales (Guichard et al. 2004). While individual reefs provide a convenient choice for analysis of fine scale dynamics, single patch populations may not be the only ecologically informative choice: strong larval dispersal within groups of reefs may couple population dynamics to the extent that these interconnected subregions also become a useful population scale. Our mechanistic understanding of marine metapopulation dynamics will therefore be advanced if we can develop systematic techniques for identifying ecologically significant scales (Levin 1992, Murdoch 1994) that are defined by the larval dispersal patterns.

In this study, we used the simulated larval dispersal dataset of James et al. (2002) to explore whether distinct subregions of the reef fish metapopulation could be identified. Two further important questions arose: (1) do these subregions also play the roles of demographic sources or sinks (Thomas \& Kunin 1999), and 
(2) if so, how do population dynamics within the source and sink regions differ? We defined a source as a population that could persist without external larval supply, and a sink as a population that could not (Pulliam 1988). This definition implies that local reproduction in a source population must exceed mortality when the population is at low abundance.

We developed systematic methods for defining appropriate ecological subregions based on analysis of dispersal datasets and we applied these techniques to reveal a natural partition in the extensive simulated larval dispersal dataset of James et al. (2002) for the Cairns section of the GBR (see Fig. 1). We investigated the implications of this structure for the fish populations, and we were especially interested in evidence for source or sink subregions and used our analysis of dispersal patterns to identify an appropriate, natural scale unit within this metapopulation.

\section{METHODS}

The methods that follow can identify large-scale larval dispersal structure, and resolve its effects on a metapopulation. They were applied here to a simulated metapopulation of reef fish on the GBR by analysing larval dispersal data from James et al. (2002). These data were generated by a numerical model that incorporated both the hydrodynamics of the physical environment, and the individual biological behaviour of the larvae. The model simulated larval dispersal pathways for all 320 reefs located between latitudes 14 and $19^{\circ} \mathrm{S}$. A numerical hydrodynamic model accounted for the effects of tides, wind, and oceanic influences on water currents within and around the shelf-reef complex. Currents were computed for each spawning season between 1967 and 1998 (modelling undertaken subsequent to the James et al. (2002) paper provided an extra $12 \mathrm{yr}$ of data.)

The general structure of the oceanic currents adjacent to the model domain is discussed in Church (1987), Burrage et al. (1995) and Hughes (2002), and is depicted schematically in Fig. 1. A broad oceanic inflow system, the South Equatorial Current (SEC), which is part of the South Pacific gyre, meets the continental shelf and bifurcates at a latitude around $16^{\circ} \mathrm{S}$, although it should be noted that the latitude of this bifurcation is subject to significant temporal variation. The SEC splits to form 2 western boundary currents whose influence is felt on the continental shelf as low frequency currents. These are the southward flowing East Australia Current (EAC), and the northward flowing New Guinea Coastal Undercurrent (NGCU; Lindstrom et al. 1987), the latter of which flows clockwise around the Gulf of Papua. The current structure within

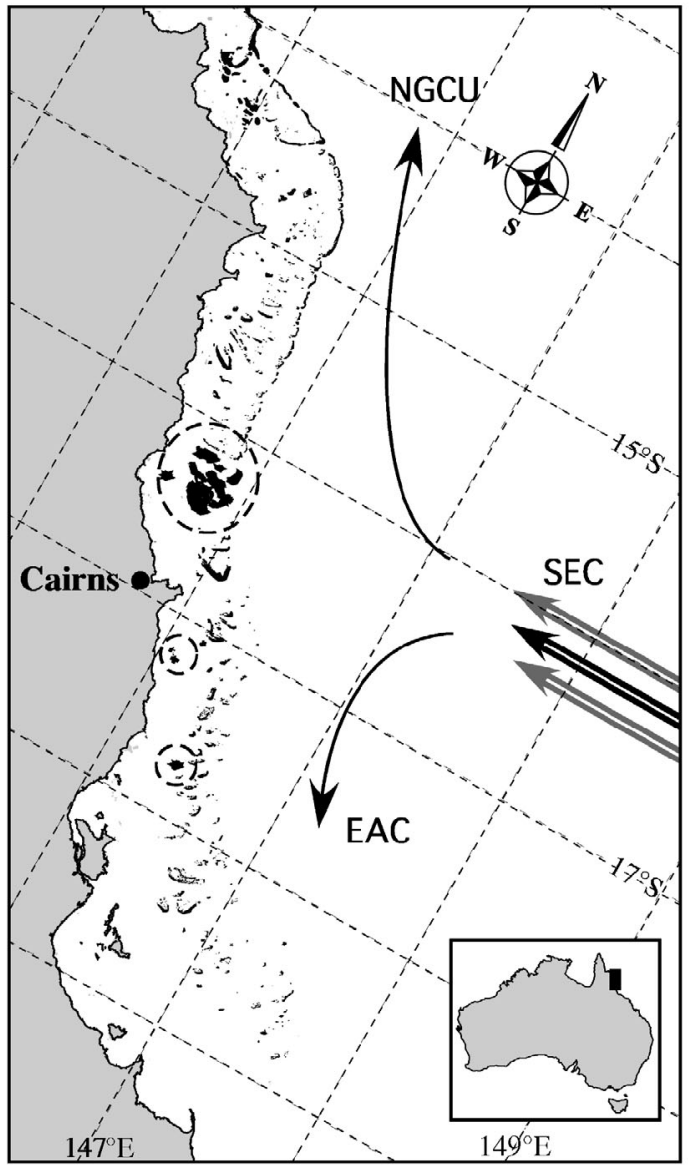

Fig. 1. Region of the GBR represented by the model. Arrows indicate general structure of the oceanic currents and approximate location of the South Equatorial Current's (SEC) bifurcation. Gateway reefs are emphasised with a darker colour and are circled with dashed lines. EAC: East Australian

Current; NGCU: New Guinea Coastal Undercurrent

the GBR lagoon is highly variable both temporally and spatially.

Spawning of reef fishes took place at each daylight high tide, with the number of larvae produced at each reef being proportional to the length of the reef perimeter. Larvae resided in the mid-water column until the development of swimming capabilities at $14 \mathrm{~d}$. After this period of passive dispersal, larvae entered an active phase, during which they would detect and approach the first reef that came within a $1 \mathrm{~km}$ sensory zone. Larvae were subject to a mortality rate of $18 \% \mathrm{~d}^{-1}$ during their entire pelagic phase.

In a given year, the origins and destinations of larvae were summarised in a connectivity matrix. Connectivity matrices provide large scale descriptions of larval movement that are easy to manipulate and analyse using linear algebra techniques (Largier 2003). Multiple spawning events were simulated each year, and 
then aggregated to yield a single seasonal connectivity matrix.

Identifying subregions. Our main interest lay in the spatial patterns of larval dispersal, and how these affected the dynamics of the metapopulation. We looked for evidence of source regions by searching for regional unidirectional larval dispersal. Initially, we searched for dispersal patterns in the individual matrices, and then investigated if this structure existed throughout the time series. If there are only 2 subregions in a system, $X$ and $Z$, and $X$ transports larvae to $Z$ but not vice versa, then $X$ must be a source subregion as it is persisting without external larval supply (i.e. without larval supply from $Z$ ). Subregion $Z$ may or may not be a sink in this case. It is possible that $Z$ depends on that external supply of larvae for its own persistence, and hence is a sink. Network analysis of connectivity matrices can detect evidence of such unidirectional dispersal.

A metapopulation can be treated as a weighted network, as proposed by Urban \& Keitt (2001): the patch populations are the vertices, and the connectivities constitute the weighted edges. The larval connectivity in a metapopulation of $n$ patches is described by an $n \times n$ connectivity matrix, $\mathbf{P}$, with elements $p_{i j}$. These represent the proportion of larvae created at patch $i$ that arrive at patch $j$ before any post-settlement mortality of recruits occurs.

Connectivity over multiple time steps can affect the dynamics of a metapopulation (Armsworth 2002). If population $i$ is connected to population $k\left(p_{i k}>0\right)$, and population $k$ is in turn connected to population $j$ ( $p_{k j}>$ $0)$, then populations $i$ and $j$ are connected indirectly. Connectivity through an intermediate population occurs over $2 \mathrm{yr}$, and hence appears in the matrix $\mathbf{P}^{2}$, where $\left[\mathbf{P}^{2}\right]_{i j}=\sum_{k=1}^{n} p_{i k} p_{k j}$. If local population $i$ cannot send larvae to population $j$, either directly or through any single intermediate population, then both $p_{i j}=0$ and $\left[\mathbf{P}^{2}\right]_{i j}=0$. In general, $\mathbf{P}^{\tau}$ contains all the $\tau$-year connectivities between reef pairs. We define the matrix $\mathbb{P}=\sum_{t=1}^{n} \mathbf{P}^{\tau}$. The elements of $\mathbb{P}$ denote the sum of all possible pathways between each pair of populations.

If a particular subregion of a persisting metapopulation did not receive any significant external larval supply, it would have to be a source subregion. It is a simple matter to search for such sources: for any population $j$ in the source subregion, and any population $i$ in the remainder of the metapopulation, $\mathbb{P}_{i j}=0$ (to within some tolerance).

A convenient method to assess whether such unidirectionality exists is to test for 'reducibility', a characteristic of matrices that has been used previously in ecology (e.g. when analysing digraph representations of age structured models; see Caswell 2001). A connectivity matrix $P$ is reducible if it can be permuted into the following form:

$$
\mathbf{P}_{R}=\mathbf{S}^{T} \mathbf{P S}=\left[\begin{array}{l|l}
\mathbf{X} & \mathbf{Y} \\
\hline 0 & \mathbf{Z}
\end{array}\right]
$$

where $\mathbf{S}$ is a permutation matrix and $\mathbf{X}$ and $\mathbf{Z}$ are square matrices. Eq. (1) implies the existence of unidirectional larval transport from the reefs in Set $X$ to the reefs in Set $Z$, and no larval transport in the reverse direction. Importantly, applying a symmetric permutation to a connectivity matrix does not alter the $p_{i j}$ values, or the dynamics of the metapopulation. Such a permutation simply reorders the local patch populations in the connectivity matrix, making its reducibility apparent.

If we can symmetrically permute a connectivity matrix into reducible form, we have immediately identified a source subregion. Furthermore, each of the block matrices in $\mathbf{P}_{R}$ has meaning for the regional metapopulation connectivity. Matrix $\mathbf{X}$ defines how the populations in the source subregion (Set $X$ ) are interconnected, i.e. the self-recruitment within this group of populations; $\mathbf{Z}$ does the same for the populations in Set $Z$. Matrix $\mathbf{Y}$ defines how much transfer there is from the populations in Set $X$ to the populations in Set $Z$, i.e. the unidirectional connectivity from the source subregion to the other subregion. The block matrix of zeros indicates that there is no transfer from $Z$ to $X$.

Population simulations. To test whether the subregions identified by this reducibility analysis are actually sources or sinks, numerical simulations of a metapopulation need to be performed. The population model used has 5 age classes (James et al. 2002), with constant probability of survival from one age class to the next. Each season the adults produce larvae, and connectivity for the system is simulated by selecting a matrix at random from the set of 32. (Analysis showed no significant autocorrelation in the time series of connectivity matrices.) Larvae that settle on a reef suffer compensatory density-dependent mortality (Steel 1997, Schmitt \& Holbrook 1999, Doherty 2002, Hixon \& Webster 2002). In the model, the number of fish in the first age cohort $N_{1}(t+1)$, relative to the number that would result from larval saturation $N_{s}$, that survive from a settlement of $L(t)$ larval fish, is calculated using a dimensionless Beverton-Holt relationship:

$$
\frac{N_{1}(t+1)}{N_{s}}=\frac{\beta L(t)}{1+\beta L(t)}
$$

where $\beta$ is a constant. This model describes the dynamics of a population with a measure of 'recruitment limitation', the extent of which depends on the value of $\beta$. A full description of the model is included in Appendix 1.

Two separate simulation experiments were performed to test the hypothesis that the 2 regions identi- 
fied by the reducibility analysis form a source-sink pair. (1) The level of recruitment limitation ( $\beta$ ) was varied and equilibrial population densities were computed for Subregions $X$ and $Z$ in isolation, and then for the full metapopulation. (2) The dependency of each subregion on the other was assessed in a perturbation experiment, as follows. The metapopulation was allowed to equilibrate, and then the population densities on each patch in 1 subregion were reduced to $10 \%$ of their equilibrium levels. The metapopulation was then allowed to recover, and the rate of recovery was observed. Once it returned to equilibrium, all patches in the other subregion were perturbed.

\section{RESULTS}

\section{Dispersal structure}

Analysis of the GBR connectivity matrices from 1967 to 1998 uncovered significant reducibility in 3 years: 1972, 1974 and 1976. This reducibility suggested that regional scale source-sink dynamics could exist within the metapopulation. The form of the reducibility indicated that connectivity in the Cairns section of the GBR was split into 2 roughly equal parts, connected by unidirectional larval dispersal. The 2 regions are separated latitudinally at $16.1^{\circ} \mathrm{S}$ (Fig. 1). So pronounced is the divide that in these 3 reducible years, the northern subregion supplied larvae to the southern subregion, but received none itself in return.

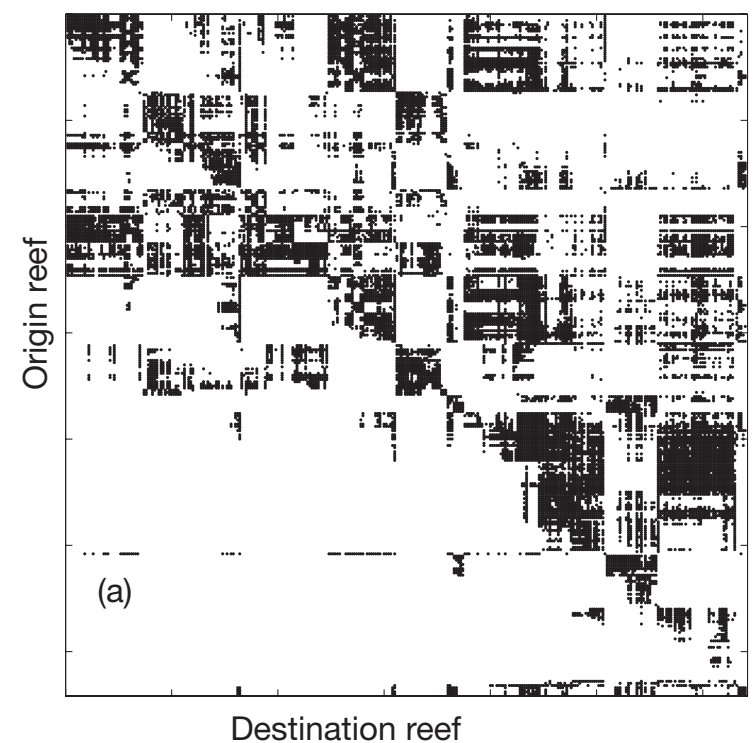

Fig. 2a shows the non-zero elements of the matrix $\mathbf{P}_{1972 ;}$ Fig. 2b shows the same matrix, symmetrically permuted into reducible form $\mathbf{P}_{1972 R}$. The zero elements of this matrix indicate pairs of populations that never exchanged larvae. The matrix $\mathbf{P}_{1972 R}$ highlights the different regions of the metapopulation. Fig. 2a,b functionally show the same matrix; both are reducible.

Connectivity matrices from years other than 1972, 1974 and 1976 were not reducible. However, when a symmetric permutation (as in Eq. 1) was applied to these irreducible connectivity matrices using $\mathbf{S}$ from a reducible year, the resulting matrix was almost in reducible form. Fig. 3 shows the connectivity matrix from 1981, before and after symmetric permutation with the matrix $\mathbf{S}_{1972}$. This outcome was representative of matrices from all 32 years.

The resulting matrix in Fig. 3b is almost in reducible form. The block matrix in the lower left (which would be completely zero in a reducible matrix, Eq. 1) contains only a few non-zero entries. Thus, although almost all the annual connectivity matrices are mathematically irreducible, they show an ecologically similar unidirectional dispersal structure to that of a reducible connectivity matrix: the relative magnitude of southerly larval dispersal between the 2 regions - i.e. from the northern to the southern subregion - was overwhelming.

\section{Gateway reefs}

The non-zero elements in the lower left block matrix in Fig. $3 \mathrm{~b}$ corresponded to a set of populations in the south-

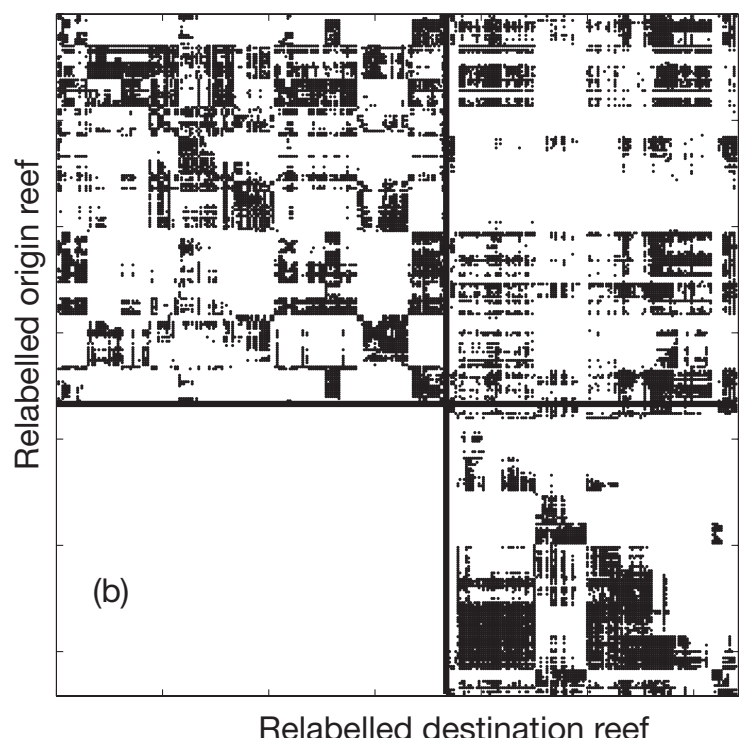

Fig. 2. (a) $\mathbf{P}_{1972}$ : connectivity matrix from 1972, where each dot indicates the presence of larval transport from the reef on the vertical axis to the reef on the horizontal axis. Self-recruitment appears on the diagonal. (b) The same matrix in reduced form after transformation by the symmetric permutation, $\mathbf{P}_{1972 R}=\mathbf{S}^{T} \mathbf{P}_{1972} \mathbf{S}$. Thick black lines were added to delineate block matrices, as shown in Eq. 1 


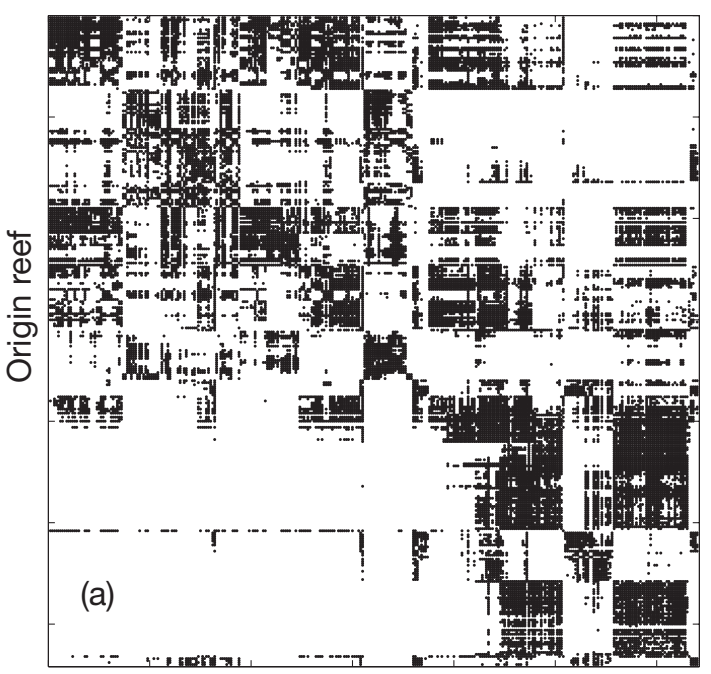

Destination reef

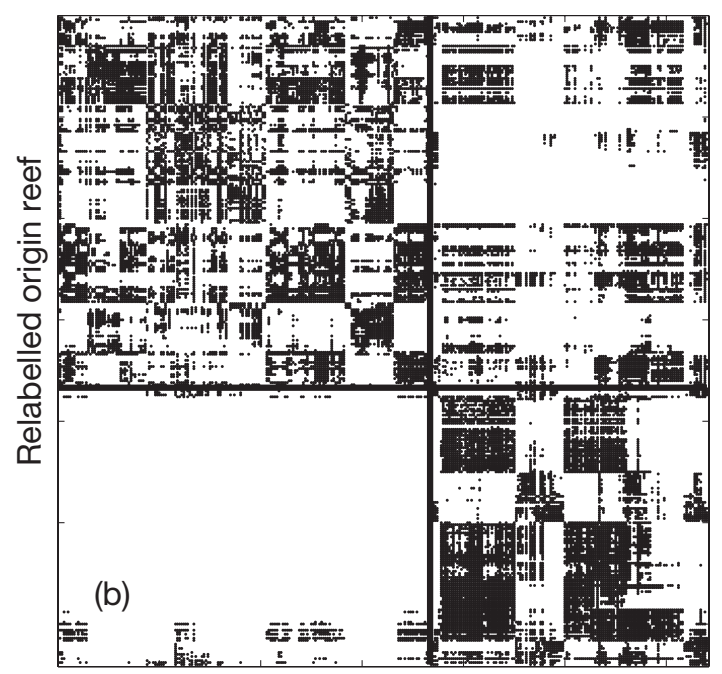

Relabelled destination reef

Fig. 3. Demonstration that non-reducible connectivity matrices can be permuted into approximately reduced form, using the permutation matrix from a reducible year $\left(\mathbf{S}_{1972}\right)$. (a) $\mathbf{P}_{1981}$ : untransformed matrix from 1981. (b) The same matrix after symmetric permutation with matrix $\mathbf{S}_{1972}$ was applied to $\mathbf{P}_{1981}$

ern subregion that were able to transport larvae to the northern subregion, against the otherwise unidirectional larval dispersal. In the 3 reducible years, no reefs south of $16.1^{\circ} \mathrm{S}$ transported larvae to the northern subregion. In the remaining years, 11 reefs accounted for at least $80 \%$ of all the larval transport from the southern to the northern subregion in any given year. These were mostly positioned on the boundary between the 2 regions, and for this reason were named Gateway reefs: Rudder Reef, Tongue Reef, Batt Reef, Opal Reef, Reef 16022, Reef 16-024, Reef 16-027, Ellison Reef, Normanby Island, High and Low Islets. They are marked on Fig. 1.

\section{Population simulations}

The population simulations emphasised the independence of the northern subregion from the southern subregion. They also verified that the northern subregion is a larval source for the southern subregion, and that the southern subregion is a larval sink. Fig. 4 shows the output of the first numerical experiment: equilibrium populations of the source and sink regions of the GBR, with and without exchange of larvae between the regions. The northern population reached the same equilibrium in each of these 2 scenarios. As the northern subregion received little larval input from the southern subregion, it was unaffected by its presence (or absence), even in conditions of extreme recruitment limitation (small $\beta$ ). Thus, not only was the northern subregion independent of larval input from the southern subregion, it could persist in conditions of recruitment limitation without external larval input, and thus constituted a larval source.
The opposite was true for the southern subregion: when the system was recruitment limited, it could not persist without larval input from the northern subregion, meaning that it was a larval sink. The northern source was able to persist in conditions for which the southern subregion alone was unsustainable. Even under conditions that allowed the southern subregion to persist independent of the north, its population levels were demonstrably increased by larval supply from the northern source.

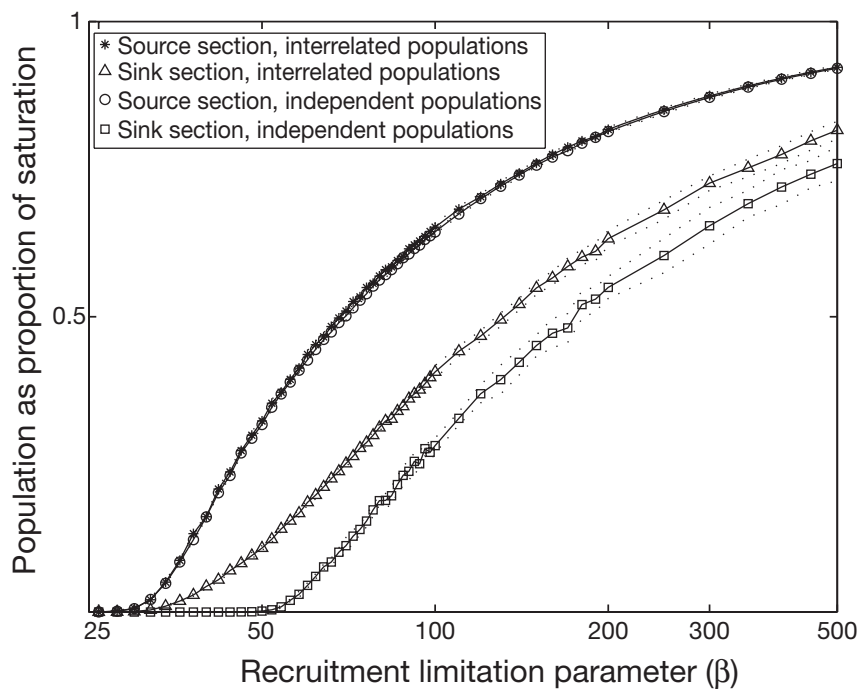

Fig. 4. Simulated equilibrium populations of the northern source and southern sink regions for different strengths of recruitment limitation (as measured by $\beta$ ). Equilibrium with and without larval exchange between the 2 regions is compared. Population measurements were averaged over all reefs in the regions. Dotted lines indicate $\pm 1 \mathrm{SD}$ 


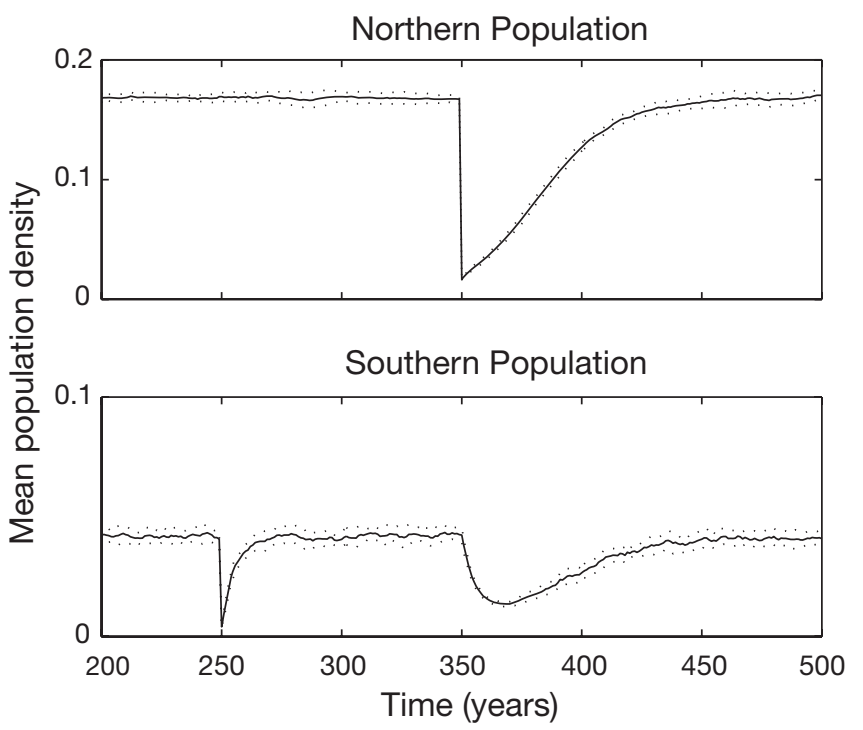

Fig. 5. Effects of perturbing one subregion of the GBR on the other. At Year 250, the southern population was reduced to $10 \%$ of its equilibrium levels, then allowed to recover. At Year 350 , the northern population was reduced in the same way. Simulation was terminated after 500 yr. Full lines: average over all 15 replicates; dotted lines: $\pm 1 \mathrm{SD}$

We also see the dependency of the subregions in Fig. 5, which shows the reaction of the northern and southern subregions of the metapopulation to drastic perturbations. After $250 \mathrm{yr}$, the population of the southern subregion was forced to drop sharply, but was able to recover rapidly as larval transport from the northern source continued at normal levels. Throughout this event, population levels in the northern subsection were unchanged, as these populations received no larval input from the southern subregion. In contrast, the recovery of the northern populations after $90 \%$ mortality (imposed at Year 350) was very slow, as they received little larval dispersal from the southern subregion, and then only via the Gateway reefs. Almost all settlement in the north came from larval dispersal within the subregion, which had been sharply reduced along with its population.

Significantly, we also noted that mortality in the northern subregion had consequences for the southern subregion. Fig. 4 shows that without larval input from the northern subregion, the population in the southern sink subregion was suppressed. In Fig. 5, when the northern subregion experienced severe mortality at Year 350, the quantity of larvae it exported to the southern subregion dropped substantially. Without this supply of larvae, the population levels of the southern subregion decreased, even though it was not exposed to any direct mortality. The southern subregion recovered slowly to its previous equilibrium only as the northern population, and with it the external supply of larvae, returned to previous levels.

\section{DISCUSSION}

Gradients in both abundance and recruitment in $\mathrm{Po}$ macentrus moluccensis prompted Doherty (2002) to suggest that populations in the north of the GBR acted as sources, supporting populations on reefs in the central and southern regions. We have shown that such regional scale source and sink structures can arise as a direct consequence of larval dispersal patterns alone. This dispersal-induced source-sink structure would apply in addition to more traditional source-sink dynamics, which result from the interaction of local specialisation of species with environmental heterogeneity.

To establish that dispersal patterns alone could induce source-sink structures, we assumed demographic homogeneity across reefs in the model. Realistically, however, environmental heterogeneity is pronounced. Environmental conditions change markedly across the continental shelf (Wilkinson \& Cheshire 1988), and large-scale abundance surveys reported by Williams (1991) showed clear cross-shelf abundance gradients for 32 pomacentrid species. However, a causal link between various environmental factors and abundance proved difficult to establish. The composition of the coral community, which also varies spatially, can affect the survival and growth of reef fishes as shown by Jones (1988) for Pomacentrus amboinensis.

This spatial variation in demographic rates could moderate rather than amplify any dispersal-induced source-sink structures. For example, Doherty (1982) observed that growth rates (and by implication fecundities) of 2 pomacentrids (Pomacentrus wardi and $P$. flavicauda) were reduced with higher recruitment densities, probably through the lower availability of food (Jones 1986). This pattern might be expected to be quite common in the northern section.

Crowder et al. (2000) showed that source-sink population dynamics are critical in siting effective marine protected areas. In contrast with our work, source and sink habitats in their model were prescribed, rather than resulting as a natural outcome of inherent structure in larval dispersal.

The consistent southward dispersal of larvae, and the effective absence of northward larval dispersal, isolated the northern subregion from external larval input. Indeed, in 3 particular years (1972, 1974 and 1976), no larvae at all were transported from the southern to the northern subregion. There appears to be nothing specific to distinguish the hydrodynamics of these years. The southerly dispersal trend agrees with observations of Acanthaster planci outbreaks in the Cairns and central sections of the GBR (Kenchington 1977, Dight et al. 1990a,b, James et al. 1990, Scandol \& James 1992). Observed outbreaks of this starfish began north of Cairns, and moved southward via larval 
dispersal, to impact sequentially over a number of years on reefs in the vicinity of Cairns (Green Island, Upolu, and Arlington), Innisfail (Gibson, Howie, Peart, and Feather) and Townsville (John Brewer). James et al. (1990) had also remarked on a strong tendency for larvae in the southern sink subregion not to be transported northward.

Using a simpler hydrodynamic model than James et al. (2002) of the same region, Scandol \& James (1992) also noted that larval dispersal patterns in the north were qualitatively different from those in the south. Based solely on modelled hydrodynamics, their analysis showed that dispersal patterns were more isotropic in the northern portion of the domain, which could be a factor that contributes to the northern subregion acting as a larval source. However, this and other earlier studies made no mention of any distinct boundary to separate northern and southern regions with diverse collective dynamics.

A number of possible explanations can be advanced for this distinct boundary. Latitude $16^{\circ} \mathrm{S}$ is the general location where the westward flowing SEC bifurcates against the GBR. This oceanic structure was explicitly modelled by James et al. (2002). Conceivably, the boundary we observed between the source and sink regions is linked to this bifurcation. Furthermore, the spatial distribution of reefs in the 2 regions is markedly different, as can be seen in Fig. 1. The continental shelf remains quite narrow to the north of the boundary, but broadens considerably to the south. The boundary also coincides with the southernmost limit of the 'ribbon reefs', which form a near-continuous barrier along the edge of the continental shelf in the northern section. South of the boundary, this barrier becomes less pronounced; consequently, the mid-shelf reefs are more directly exposed to oceanic influences.

The role of the gateway reefs in the metapopulation is critical. By allowing larval transport from the southern sink subregion into the northern source subregion, these reefs maintain the integrity of the metapopulation. Effectively, all transfer from the sink to the source occurs via the gateway reefs. If they were removed from the system, the source subregion could never receive significant quantities of larvae from the sink, leaving the northern subregion isolated. Although they transport only small quantities of larvae, removal of gateway reefs would impede the transfer of genetic information from the southern to the northern subregion.

James et al. (2002) showed that the predictions of their model were robust to a range of biological assumptions (e.g. spawning schedules, competent periods, sensory zone size). Hence the results obtained here should apply to other reef fishes on the GBR, including important commercial species. The impor- tance of source-sink structure on marine reserve management has been established by Crowder et al. (2000), although there are many other factors that must be considered in marine reserve design and management. However, in allowing for the effects of recruitment dynamics on management, the source nature of the northern subregion means that management there must be necessarily more cautious, as the costs of mismanagement will be much greater.

Objective insight into a metapopulation's dynamics can be gained by an analysis that is focussed on complex patch connectivity, as this allows larval dispersal to autonomously define important scales and features. Based on such analyses, we have demonstrated that reef fish populations on the GBR exhibit large scale source-sink structure. Furthermore, not only have we shown that there are identifiably distinct subregions in the reef fish metapopulation, but also that these subregions interact and display interdependence on a regional scale.

Pelagic larval dispersal that connects patchily distributed adult populations is a feature of many marine systems. The effect of the resultant heterogeneous dispersal structure on population dynamics remains poorly understood, and yet is crucial for effective management of these valuable systems (Guichard et al. 2004). As shown in this paper, larval dispersal patterns can be highly directional, a quality not captured if inter-reserve distance alone is used as a surrogate for connectivity strength (e.g. Sala et al. 2002). Such methods may advise protecting subsections of the metapopulation that cannot independently persist - i.e. reserve networks that are larval sinks.

Preserving marine metapopulations is a pressing issue worldwide, and cannot be effectively achieved without an understanding of inter-patch connectivity. The existence of source and sink regions is a particularly simple premise, compared with the complex and temporally variable nature of larval dispersal patterns. Nevertheless, the potential impact of such structure on the effectiveness of management is most significant.

Acknowledgements. We thank A. Abdulla, S. Belward, S. Connolly, P. Doherty, S. Kininmonth, and H. Possingham for their valuable comments. We are especially grateful to M. James and L. Mason for their input and support, and access to the connectivity dataset.

\section{LITERATURE CITED}

Armsworth PR (2002) Recruitment limitation, population regulation and larval connectivity in reef fish metapopulations. Ecology 83:1092-1104

Botsford LW, Fiorenza M, Hastings A (2003) Principles for the design of marine reserves. Ecol Appl 13:S25-S31 
Burrage DM, Hughes RD, Bode L, Williams DMcB (1995) Dynamic features and transports of the Coral Sea circulation. In: Bellwood O, Choat H, Saxena N (eds) Proc Pacific Congress Mar Sci Technol PACON 94, Townsville, p 95-105

Caley MJ (1995) Reef fish community structure and dynamics: an interaction between local and larger-scale processes? Mar Ecol Prog Ser 129:19-29

Caley MJ, Carr MH, Hixon MA, Hughes TP, Jones GP, Menge BA (1996) Recruitment and the local dynamics of open marine populations. Annu Rev Ecol Syst 27:477-500

Caswell H (2001) Matrix population models: construction, analysis and interpretation, 2nd edn. Sinauer Association, Sunderland, MA

Church JA (1987) The East Australian Current adjacent to the Great Barrier Reef. Aust J Mar Freshw Res 38:671-683

Crowder LB, Lyman SJ, Figueira WF, Priddy J (2000) Sourcesink population dynamics and the problem of siting marine reserves. Bull Mar Sci 66:799-820

Dight IJ, Bode L, James MK (1990a) Modelling the larval dispersal of Acanthaster planci. I. Large scale hydrodynamics, Cairns section, Great Barrier Reef Marine Park. Coral Reefs 9:115-123

Dight IJ, James MK, Bode L (1990b) Modelling the larval dispersal of Acanthaster planci. II. Patterns of reef connectivity. Coral Reefs 9:125-134

Doherty PJ (1982) Some effects of density on the juveniles of two species of tropical, territorial damselfish. J Exp Mar Biol Ecol 65:249-261

Doherty PJ (1991) Spatial and temporal patterns in recruitment. In: Sale PF (ed) The ecology of fishes on coral reefs. Academic Press, San Diego, CA, p 261-293

Doherty PJ (2002) Variable replenishment and the dynamics of reef fish populations. In: Sale PF (ed) Coral reef fishes: dynamics and diversity in a complex ecosystem. Academic Press, San Diego, CA, p 327-355

Doherty PJ, Fowler AJ (1994) An empirical test of recruitment limitation in a coral reef fish. Science 263:935-939

Guichard F, Levin SA, Hastings A, Siegel D (2004) Towards a dynamic metacommunity approach to marine reserve theory. Bioscience 54:1003-1011

Hanski I (1999) Metapopulation ecology. Oxford University Press, New York

Hixon MA, Webster MS (2002) Density dependence in reef fishes: coral-reef populations as model systems. In: Sale PF (ed) Coral reef fishes: dynamics and diversity in a complex ecosystem. Academic Press, San Diego, CA, p 303-325

Hughes CW (2002) Zonal jets in and near the Coral Sea, seen by satellite altimetry. Geophys Res Lett 29:1-4

James MK, Dight IJ, Bode L (1990) Great Barrier Reef hydrodynamics, reef connectivity and Acanthaster population dynamics. In: Bradbury R (ed) Acanthaster and the coral reef: a theoretical perspective. Springer-Verlag, Berlin, p $17-44$
James MK, Armsworth PR, Mason LB, Bode L (2002) The structure of reef fish metapopulations: modelling larval dispersal and retention patterns. Proc R Soc Lond B 269:2079-2086

Jones GP (1986) Food availability affects growth in a coral reef fish. Oecologia 70:136-139

Jones GP (1988) Experimental evaluation of the effects of habitat structure and competitive interactions on the juveniles of two coral reef fishes. J Exp Mar Biol Ecol 123:115-126

Jones GP (1991) Postrecruitment processes in the ecology of coral reef fish populations: a multifactorial perspective. In: Sale PF (ed) The ecology of fishes on coral reefs. Academic Press, San Diego, CA, p 294-328

Kenchington RA (1977) Growth and recruitment of Acanthaster planci on the Great Barrier Reef. Biol Conserv 11:103-118

Largier JL (2003) Considerations in estimating larval dispersal distances from oceanographic data. Ecol Appl 15:S71-S86

Levin SA (1992) The problem of pattern and scale in ecology. Ecology 73:1943-1967

Lindstrom E, Lukas R, Fine R, Firing E, Godfrey JS, Meyers G, Tsuchiya M (1987) The western equatorial Pacific Ocean circulation study. Nature 330:533-537

Murdoch WW (1994) Population regulation in theory and practice. Ecology 75:271-287

Pulliam HR (1988) Sources, sinks and population regulation. Am Nat 132:652-661

Roughgarden J, Iwasa Y, Blaxter C (1985) Demographic theory for an open marine population with space-limited recruitment. Ecology 66:54-67

Sala E, Aburto-Oropeza O, Paredes G, Parra I, Barrera JC, Dayton PK (2002) A general model for designing networks of marine reserves. Science 298:1991-1993

Scandol JP, James MK (1992) Hydrodynamics and larval dispersal: a population model of Acanthaster planci on the Great Barrier Reef. Aust J Mar Freshw Res 43:583-596

Schmitt RJ, Holbrook SJ (1999) Mortality of juvenile damselfish: implications for assessing processes that determine abundance. Ecology 80:35-50

Steel MA (1997) Population regulation by post-settlement mortality in two temperate reef fishes. Oecologia 112: $64-74$

Thomas CD, Kunin WE (1999) Spatial structure. J Anim Ecol 68:647-657

Urban D, Keitt T (2001) Landscape connectivity: a graph theory perspective. Ecology 82:1205-1218

Wilkinson CR, Cheshire AC (1988) Cross shelf variations in coral reef structure and function-influences of land and ocean. Proc 6th Int Coral Reef Symp 1:227-233

Williams DM (1991) Patterns and process in the distribution of coral reef fishes. In: Sale PF (ed) The ecology of fishes on coral reefs. Academic Press, San Diego, CA, p 437-474 
Appendix 1. Metapopulation model: nondimensionalisation

To simulate the metapopulation, we used an age structured Leslie matrix model, with density dependence at the time of larval settlement, using randomly selected connectivity matrices, to define the larval dispersal. Density dependence followed the Beverton-Holt relationship:

$$
N_{j}(t+1)=\Gamma\left(S_{j}(t)\right)=\frac{\gamma S_{j}(t)}{1+\beta S_{j}(t)}
$$

where $N_{j}(t)$ is the population on reef $j$ at time $t, S_{j}(t)$ is the number of fish attempting to settle on reef $j, \Gamma$ represents the Beverton-Holt function, and $\gamma$ and $\beta$ are its 2 parameters.

Thus the number of fish surviving the first census at any reef $j$ is

$$
N_{j}(t+1)=\Gamma\left(S_{j}(t)\right)=\frac{\gamma R\left(\sum_{k=1}^{n} p_{k j}(t) N_{k}(t)\right)}{1+\beta R\left(\sum_{k=1}^{n} p_{k j}(t) N_{k}(t)\right)}
$$

where $R$ is the net reproductive value of an individual fish (Caswell 2001).

This metapopulation model can be nondimensionalised as follows. Density dependence will be a function of the settling larval density, rather than the number of settling larvae, so if a reef is saturated with larvae, $S(t) \rightarrow \infty$,

$$
N_{s}=\frac{\gamma}{\beta}
$$

which is denoted as the saturation density.

Using Eqs. (A1) \& (A3)

$$
\frac{N_{1}(t+1)}{N_{s}}=\frac{\beta S(t)}{1+\beta S(t)}=F(t)
$$

Since a constant proportion of the settling cohort survives each year, the population density at any time is dependent on the number of fish settling in the last $(\omega-1)$ years, where $\omega$ is the maximum age of the fish. (The present modelling uses $\omega=5$.)

The population density at any time is therefore

$$
N_{i}(t)=\sum_{i=1}^{\omega} q^{i-1} N_{i}(t-i+1)=\sum_{i=1}^{\omega} N_{s} q^{i-1} F(t-i)
$$

where $q$ is the constant probability that an individual survives to the next age class. For the entire metapopulation, we can use the above equations to construct a dimensionless analogue to Eq. (A2). The number of larvae arriving per unit area from a reef $a$ to a particular reef $b$ is called the transport density and can be expressed as:

$$
T_{a b}=\frac{p_{a b}(t) A_{a}}{A_{b}} f_{1} \sum_{i=\text { mat }}^{\omega} q^{i-1} \phi_{i} N_{a}(t-i+1)
$$

where $A_{b}$ is the area of reef $b_{1} \phi_{i}$ is the fecundity of the ith age class, relative to $f_{1}$, the fecundity of the first age class, mat is the age of reproductive maturity, and $N_{a}(t)$ is the number of fish in the first age class on reef $a$ at time $t$.

The total settling cohort on reef $b$ is defined as:

$$
Z_{b}=\sum_{a=1}^{n} T_{a b}
$$

We divide $Z_{b}$ by the maximum possible larval density arriving at reef $b$, and thus eliminate the absolute fecundity. The new variable, $Z^{\prime}$, is the larval supply density, relative to the maximum possible larval supply density. Thus

$$
\begin{aligned}
Z_{b}^{\prime}= & \frac{\sum_{a=1}^{M} \frac{p_{a b}(t) A_{a}}{A_{b}} f_{1} \sum_{i=m a t}^{\omega} \phi_{i} q^{i-1} N_{s} F_{a}(t-i)}{f_{1} \sum_{i=m a t}^{\omega} \phi_{i} q^{i-1} N_{s}} \\
= & \frac{\sum_{a=1}^{M} \frac{p_{a b}(t) A_{a}}{A_{b}} \sum_{i=m a t}^{\omega} \phi_{i} q^{i-1} F_{a}(t-i)}{\sum_{i=m a t}^{\omega} \phi_{i} q^{i-1}}
\end{aligned}
$$

This provides us with a significantly simpler expression for the number density of first generation individuals, relative to the maximum number at that particular reef:

$$
F(t)=\frac{\beta^{\prime} Z^{\prime}(t)}{1+\beta^{\prime} Z^{\prime}(t)}
$$

For simplicity, the new dimensionless parameter, $\beta^{\prime}$, is referred to in the text of the paper as $\beta$. 